\title{
Anti-plasmodial activity of Dicoma tomentosa (Asteraceae) and identification of urospermal A-15-O-acetate as the main active compound
}

Olivia Jansen ${ }^{1 *}$, Monique Tits ${ }^{1}$, Luc Angenot ${ }^{1}$, Jean-Pierre Nicolas ${ }^{2}$, Patrick De Mol${ }^{3}$, Jean-Baptiste Nikiema ${ }^{4}$ and Michel Frédérich ${ }^{1}$

\begin{abstract}
Background: Natural products could play an important role in the challenge to discover new anti-malarial drugs. In a previous study, Dicoma tomentosa (Asteraceae) was selected for its promising anti-plasmodial activity after a preliminary screening of several plants traditionally used in Burkina Faso to treat malaria. The aim of the present study was to further investigate the anti-plasmodial properties of this plant and to isolate the active anti-plasmodial compounds.

Methods: Eight crude extracts obtained from D. tomentosa whole plant were tested in vitro against two Plasmodium falciparum strains (3D7 and W2) using the p-LDH assay (colorimetric method). The Peters' four-days suppressive test model (Plasmodium berghei-infected mice) was used to evaluate the in vivo anti-plasmodial activity. An in vitro bioguided fractionation was undertaken on a dichloromethane extract, using preparative HPLC and TLC techniques. The identity of the pure compound was assessed using UV, MS and NMR spectroscopic analysis. In vitro cytotoxicity against WI38 human fibroblasts (WST-1 assay) and haemolytic activity were also evaluated for extracts and pure compounds in order to check selectivity.
\end{abstract}

Results: The best in vitro anti-plasmodial results were obtained with the dichloromethane, diethylether, ethylacetate and methanol extracts, which exhibited a high activity $\left(\mathrm{IC}_{50} \leq 5 \mu \mathrm{g} / \mathrm{ml}\right)$. Hot water and hydroethanolic extracts also showed a good activity $\left(\mathrm{IC}_{50} \leq 15 \mu \mathrm{g} / \mathrm{ml}\right)$, which confirmed the traditional use and the promising anti-malarial potential of the plant. The activity was also confirmed in vivo for all tested extracts. However, most of the active extracts also exhibited cytotoxic activity, but no extract was found to display any haemolytic activity. The bioguided fractionation process allowed to isolate and identify a sesquiterpene lactone (urospermal A-15-O-acetate) as the major anti-plasmodial compound of the plant ( $\mathrm{IC}_{50}<1 \mu \mathrm{g} / \mathrm{ml}$ against both 3D7 and W2 strains). This was also found to be the main cytotoxic compound $(S I=3.3)$. While this melampolide has already been described in the plant, this paper is the first report on the biological properties of this compound.

Conclusions: The present study highlighted the very promising anti-plasmodial activity of D. tomentosa and enabled to identify its main active compound, urospermal A-15-O-acetate. The high anti-plasmodial activity of this compound merits further study about its anti-plasmodial mechanism of action. The active extracts of $D$. tomentosa, as well as urospermal A 15-O-acetate, displayed only a moderate selectivity, and further studies are needed to assess the safety of the use of the plant by the local population.

Keywords: Antiplasmodial, Asteraceae, Melampolide, Burkina Faso, Dicoma tomentosa, Natural compound

\footnotetext{
* Correspondence: ojansen@ulg.ac.be

'Laboratoire de Pharmacognosie, Centre Interfacultaire de Recherche du Médicament (CIRM), Université de Liège, Av. de I'Hôpital 1, CHU-B36, B-4000 Liège, Belgium

Full list of author information is available at the end of the article
}

\section{() Biomed Central}

(c) 2012 Jansen et al.; licensee BioMed Central Ltd. This is an Open Access article distributed under the terms of the Creative Commons Attribution License (http://creativecommons.org/licenses/by/2.0), which permits unrestricted use, distribution, and reproduction in any medium, provided the original work is properly cited. 


\section{Background}

Chemotherapeutic treatment of malaria has evolved in the last ten years due to the spread of multi-resistant Plasmodium falciparum strains. The World Health Organization (WHO) currently promotes artemisinin-based combination therapy $(\mathrm{ACT})$ as the reference medicine for health care management of uncomplicated falciparum malaria in order to reduce the risk of resistance [1]. However, some signs of resistance to artemisinin have recently been detected in Asia [2-4], representing an enormous threat for the control of the disease. The discovery of new anti-malarial drugs is urgently needed and natural products could play an important role in this new challenge.

The plant kingdom has been and remains a good source of pharmacologically active compounds and especially anti-plasmodial agents, as attested by quinine, isolated from Cinchona sp., and artemisinin extracted from Artemisia апnиa. Besides these well-known examples, various new anti-plasmodial natural compounds are frequently being discovered, as reviewed by several authors in recent years [5-9].

WHO estimates that up to $80 \%$ of the world's population relies on traditional medicinal products for some aspects of primary health care [10,11]. Many people living in developing countries do not have access to modern therapeutics, such as ACT, to treat malaria because of financial, socio-economical, geographical and/or cultural reasons, and they use plants, often in combination, for the health care management of malaria.

The search for new anti-malarial natural products, following an ethnopharmacological strategy (based on traditional knowledge of plants), has led to interesting results, as reviewed and commented on by Willcox et al. $[12,13]$.

Moreover, there is now evidence that some whole plant extracts can be more active than single compounds, as a result of synergy and positive interactions between different constituents in the extracts, compared to a single product $[14,15]$.

In this context, the pharmacological and phytochemical study of plants from traditional pharmacopoeias can be of interest, not only in discovering new anti-malarial "lead compounds", but also in valorizing local vegetal species whose efficacy and safety has been demonstrated in laboratory and clinical investigations [16].

Better knowledge of plants from traditional pharmacopoeias and local valorization of traditional remedies in improved traditional medicine (ITM) could lead to effective, standardized, available and affordable therapeutics for the management of malaria by local populations, when modern drugs are unavailable [17].

Validated anti-malarial phytomedicines formulated from traditional medicines have been reported in recent years. Some are government approved in different countries, e g, Argemone mexicana in Mali, whose anti-malarial activity has been confirmed in clinical trials [18], and "Saye" in Burkina Faso, a combination of three plants, used for several years as a curative anti-malarial and recently studied for its benefits in the prophylaxis of malaria [19].

In a previous study dealing with the screening of several plants used in Burkina Faso in the traditional treatment of malaria, Dicoma tomentosa was selected for its promising anti-plasmodial activity [20].

Dicoma tomentosa is a plant of the Asteraceae family growing in Asia and tropical Africa. It is an uncommon species, mainly found in the Sahelo-Sudanian area. Called "Gômtigdà" in the local language (Mooré), the decoction of the whole plant is traditionally used in Burkina Faso to treat malaria in adults and children, particularly malaria with spleen and liver "inflammation" [21]. The plant is also known for its benefits against cough and in postnatal care to "wash the belly", but it is not recommended for pregnant women because it is known to cause abortion.

The plant has been described as containing several sesquiterpene lactones [22-24], triterpenes and sterols [25,26] as well as flavonoids [27-30], but has never been studied for any biological or pharmacological properties.

The aim of the present study was to further evaluate the anti-plasmodial potential of $D$. tomentosa using in vitro and in vivo models. In vitro cytotoxic and haemolytic properties were also studied in order to check the selectivity of the plant and thereby to appreciate its safety of use.

Finally, a bioguided fractionation was undertaken to complete the study. This phytochemical analysis led to the isolation and identification of the major active compound.

\section{Methods}

Plant material

Dicoma tomentosa whole plant (400 g) was collected in Poun, province of Sanguié, Burkina Faso in October 2008. The sample was authenticated by the Herbarium of the National Botanic Garden of Belgium, at Meise (Belgium). A voucher specimen was deposited in the same Herbarium under the number BR0000005088959. The plant material was washed and dried in a ventilated room $\left(30^{\circ} \mathrm{C}\right)$ and then ground to a powder.

\section{Preparation of crude extracts}

Eight crude extracts were prepared using eight different solvents: petroleum ether, hexane, dichloromethane, diethylether, ethylacetate, methanol, ethanol/water $(50 \%, \mathrm{v} / \mathrm{v})$ and hot water. For each solvent, $5 \mathrm{~g}$ of dried plant powder were macerated with $50 \mathrm{ml}$ of solvent, while being shaken for 30 minutes with a magnetic stirrer. This step was repeated twice. The preparations were filtered and evaporated under reduced pressure.

For the aqueous crude extract, we prepared a decoction of $5 \mathrm{~g}$ dried plant powder in $150 \mathrm{ml}$ distilled water for $90 \mathrm{~min}$ in order to approximate the traditional preparation 
method. The preparation was then filtered and freeze dried.

\section{In vitro anti-plasmodial assays Culture}

Continuous cultures of $P$. falciparum, chloroquine-sensitive (3D7) and chloroquine-resistant (W2) strains were maintained as described by Frédérich et al. [31]. Both strains were obtained from Prof Grellier (Museum National d'Histoire Naturelle, Paris, France).

\section{Assay}

The in vitro anti-plasmodial assay reproduces the erythrocytic development stage of the parasite and was performed as previously described [20]. Each of the eight crude extracts was first dissolved in DMSO (Sigma) at a concentration of $10 \mathrm{mg} / \mathrm{ml}(5 \mathrm{mg} / \mathrm{ml}$ for pure compound). Plasmodium falciparum culture was placed in contact with a set of eight two-fold dilutions in the medium of each extract on two columns of a 96-well microplate for $48 \mathrm{~h}$ (final concentrations ranging from $0.8(0.4)$ to $100(50) \mu \mathrm{g} /$ $\mathrm{ml}$ and final DMSO concentration $\leq 1 \%$, each condition in duplicate). Parasite growth was estimated by colorimetric revelation and measurement of absorbance at $630 \mathrm{~nm}$ with a multiwell scanner (Stat Fax 2100, Awareness Technology Inc). The test is based on the evaluation of the plasmodial lactate dehydrogenase (pLDH) activity and was performed according to the method of Makler et al. [32] and as described previously by Kenmogne et al. [33]. Artemisinin (Sigma-Aldrich) and chloroquine (Sigma-Aldrich) were used as positive standards, and infected and uninfected erythrocytes were added as positive and negative controls, respectively. The inhibition of growth was calculated by comparison with the infected non-treated erythrocytes ( $=100 \%$ growth). $\mathrm{IC}_{50}$ values, indicating the concentration of the drug needed to obtain $50 \%$ inhibition of parasite growth, were calculated by linear regression from a set of eight concentrations tested for each extract/pure compound. Each sample was tested three times (3 independent assays, $\mathrm{n}=3$ ) for each plasmodial strain.

In line with $\mathrm{WHO}$ guidelines and basic criteria for antiparasitic drug discovery [34,35], activities of extracts were classified into four classes according to their $\mathrm{IC}_{50}$ values: high activity $\left(\mathrm{IC}_{50} \leq 5 \mu \mathrm{g} / \mathrm{ml}\right) ;$ promising activity $\left(5 \mu \mathrm{g} / \mathrm{ml}<\mathrm{IC}_{50}\right.$ $\leq 15 \mu \mathrm{g} / \mathrm{ml})$; moderate activity $\left(15 \mu \mathrm{g} / \mathrm{ml}<\mathrm{IC}_{50} \leq 50 \mu \mathrm{g} / \mathrm{ml}\right)$; weak activity $\left(\mathrm{IC}_{50}>50 \mu \mathrm{g} / \mathrm{ml}\right)$. A pure compound is defined as highly active when its $\mathrm{IC}_{50} \leq 1 \mu \mathrm{g} / \mathrm{ml}$.

\section{In vitro cytotoxicity assays \\ Culture}

WI-38 normal human foetal lung fibroblasts were maintained in continuous culture in DMEM medium (Bio Whittaker) in a humid atmosphere at $37^{\circ} \mathrm{C}$ and $5.5 \% \mathrm{CO}_{2}$. Each medium was supplemented with $10 \%$ heat-inactivated foetal bovine serum (Bio Whittaker), 1\% L-glutamine (200 mM) (Bio Whittaker) and antibiotics: penicillin (100 $\mathrm{UI} / \mathrm{ml})$ - streptomycin $(100 \mu \mathrm{g} / \mathrm{ml}) \quad$ (Pen-strep $^{\circledR}$, Bio Whittaker).

\section{Assays}

Each of the eight crude extracts was first dissolved in DMSO (Sigma) to a concentration of $10 \mathrm{mg} / \mathrm{ml}(5 \mathrm{mg} / \mathrm{ml}$ for pure compound). For the assays, 96-well tissue culture microplates (Micro Test- $96^{\circledR}$, Falcon, Becton-Dickinson) were seeded with $200 \mu \mathrm{l}$ medium containing 8,000 cells in suspension.

After $24 \mathrm{~h}$ incubation, cells were treated with six dilutions at a final concentration of crude extracts in culture medium of $1,5,10,25,50$ and $100 \mu \mathrm{g} / \mathrm{ml}$ (half concentration for pure compounds) and a final DMSO concentration $\leq 1 \%$. After $48 \mathrm{~h}$ incubation, cell viability was determined by adding WST-1 (Roche Biomolecular) tetrazolium salt as a cytotoxicity indicator and by reading absorbance at $450 \mathrm{~nm}$ with a scanning multiwell spectrophotometer (Stat Fax 2100, Awareness Technology Inc) after about a onehour wait. Tetrazolium salts are cleaved to formazan dye by cellular enzymes. The absorbance directly correlates to the viable cell number. Each condition was reproduced in triplicate and each set of tests was performed twice. Camptothecin (Sigma-Aldrich) was used as a positive cytotoxic control. The inhibition of growth was calculated by comparison with the negative control (non-treated cells). $\mathrm{IC}_{50}$ values, indicating the concentration of the drug needed to obtain $50 \%$ inhibition of cell growth, were calculated by linear regression from a set of six concentrations tested for each extract.

\section{Selectivity index (SI)}

The SI value allows the evaluation of the selective activity of the extracts/pure compound against the parasite compared to its toxicity for human cells. The SI value is calculated as the ratio between cytotoxic $\mathrm{IC}_{50}$ values and $3 \mathrm{D} 7$ or $\mathrm{W} 2$ parasitic $\mathrm{IC}_{50}$ values.

\section{In vitro haemolysis assays}

Haemolysis assays were conducted with the eight crude extracts and isolated pure compound, according to a previously described procedure [36]. Briefly, red blood cells suspensions $(10 \%$ in PBS $(\mathrm{v} / \mathrm{v}))$ were incubated under agitation at room temperature for one hour with extract or pure compound solutions (final concentration $=100 \mu \mathrm{g} / \mathrm{ml}$ and DMSO $<1 \%$ ). The mixtures were then centrifuged at room temperature for $5 \mathrm{~min}$ at 10,000 $\times \mathrm{g}$ and the absorbance (OD) of the supernatants was measured at $550 \mathrm{~nm}$ with a microplate reader (Stat Fax 2100, Awareness Technology Inc). The crude extracts/pure compound were tested in triplicate at a final concentration of $100 \mu \mathrm{g} / \mathrm{ml}$. Triton X-100 1\% (v/v) was used as a positive control (100\% 
red blood cell lysis) and PBS as a negative control (0\% red blood cell lysis). The red blood cell lysis percentage $(\mathrm{H})$ was determined as follows: $\mathrm{H}=(\mathrm{OD} 550 \mathrm{~nm}$ sample - OD550nm PBS)/(OD550nm Triton X-100 1\% - OD550nm PBS). The results were expressed as means $\pm S D$ with $n=3$.

\section{In vivo anti-plasmodial assays}

The present study was approved by the Ethical Committee for the use of laboratory animals at the University of Liège (no. 721) and was designed according to the internationally recognized guidelines. Methanol, hydroethanolic and aqueous extracts of $D$. tomentosa were tested using a test protocol based on the four-day suppressive test of Peters [35]. Female Swiss mice (10 weeks of age, $25 \pm 2$ g), obtained from Charles River Laboratories (Brussels), were infected by the rodent parasite Plasmodium berghei NK173, following the protocol described in Frederich et al. [37]. Groups of five mice were formed randomly. The treatment doses $(100 \mathrm{mg} / \mathrm{kg}$ ip or $300 \mathrm{mg} / \mathrm{kg}$ po, dissolved in 7\% Tween 80 and 3\% ethanol) were given intraperitoneally (methanol and hydroethanolic extracts) or orally (hydroethanolic and aqueous extracts), four hours after infection (day 0). The treatment was repeated once daily for the next three days (on days 1, 2 and 3 post-infection). On day 4 and day 7, thin blood smears were made from mouse-tail blood and were stained with Giemsa. Slides were inspected under the microscope and parasitaemia was determined by counting at least 500 erythrocytes. Mice were controlled for their mortality for two weeks. Chloroquine diphosphate salt at $4 \mathrm{mg} / \mathrm{kg}$ (ip) was used as positive control and a methanol extract of the bark of Cinchona succirubra at $200 \mathrm{mg} / \mathrm{kg}$ (ip) was used as "positive plant extract control" due to the known presence of quinine in this Cinchona bark extract. This was used as a supplemental positive control to observe the profile of inhibition with a plant extract containing a known active ingredient. The vehicle solution (7\% Tween 80 and 3\% ethanol) was used as a negative control.

Inhibition of Plasmodium growth (\%) was calculated by comparison of the parasitaemia counted for the test group with the parasitaemia in the negative control group, at days 4 and 7, respectively. Except for extracts tested by the oral route, which were tested once, the experiment was performed twice and the results represent means of inhibition of parasitaemia obtained for both experiments.

\section{Bioguided fractionation Extraction}

$60 \mathrm{~g}$ of $D$. tomentosa whole plant powder were first percolated with $0.9 \mathrm{l}$ of hexane followed by $1.8 \mathrm{l}$ of dichloromethane to give $1.1 \mathrm{~g}$ of hexane extract (E1) and $1.9 \mathrm{~g}$ of dichloromethane extract (E2), respectively (yield E2 $=3.1 \%$ $(\mathrm{w} / \mathrm{w}))$.

\section{TLC analysis}

Extracts and fractions were analysed by thin layer chromatography on Si60 silica gel plate (Merck) using dichloromethane-methanol (95:5) as the mobile phase. The plates were observed under UV light (254 and $366 \mathrm{~nm}$ ) and then revealed by spraying of sulphuric vanillin reagent $(2 \%$ in ethanol $(\mathrm{w} / \mathrm{v}))$ and heating at $105^{\circ} \mathrm{C}$ for $10 \mathrm{~min}$.

\section{Preparative HPLC}

$300 \mathrm{mg}$ of the dichloromethane extract (E2) were dissolved in $11 \mathrm{ml}$ of methanol-water (50:50). The solution was centrifuged, filtered $(0.45 \mu$ membrane $)$ and injected into a reversed-phase preparative HPLC system using a Lichrospher RP-18 column $(2.5 \times 25$ cm; $12-15 \mu$, Merck packing system) as the stationary phase. The mobile phase consisted of methanol-water (50:50) in isocratic elution with a flow rate of $20 \mathrm{ml} / \mathrm{min}$ (Armen pump). Fractions of $10 \mathrm{ml}$ were collected (Büchi fraction collector) and separation was monitored by TLC analysis. Fractions with the same TLC profiles were assembled to finally give 16 fractions, designated F1 to F16. F16 (99.8 mg) was the insoluble part of the extract collected on the filter. F4 (10.2 mg) and F5 (67.3 mg) contained the main compound of the extract, as shown by TLC analysis.

\section{Preparative TLC}

$10.2 \mathrm{mg}$ of $\mathrm{F} 4$ were dissolved in $0.5 \mathrm{ml}$ of dichloromethane and deposited on a preparative Si60 TLC plate $(1.5 \mathrm{~mm} \times 20 \mathrm{~cm} \times 20 \mathrm{~cm})$. Elution was performed with dichloromethane-methanol $(95: 5)$ as the mobile phase. The band corresponding to the pure compound $\mathbf{1}$ was scratched off and extracted with a mixture of dichloromethane and methanol (50:50) using a G4 filter. The filtrate was evaporated under reduced pressure to give $8.0 \mathrm{mg}$ of the pure compound $\mathbf{1}$ = urospermal-15-O-acetate. The same procedure was applied to $9.7 \mathrm{mg}$ of F5 to give $7.8 \mathrm{mg}$ of $\mathbf{1}$.

\section{Spectroscopic analysis}

The structure of compound 1 was elucidated using various spectroscopic techniques. NMR spectra $\left({ }^{1} \mathrm{H},{ }^{13} \mathrm{C}\right.$, COSY, $\mathrm{HMBC}, \mathrm{HSQC}$ ) were recorded in $\mathrm{CDCl}_{3}$ with a Bruker Avance $500 \mathrm{MHz}$ spectrometer equipped with a cryoprobe and using TMS as the internal reference. Mass spectrometry (MS) was carried out using a micromass ESI-Q-TOF II instrument (Waters) using ESI-ionization in positive mode. The UV spectrum was obtained with a methanol solution using a Kontron Uvikon Spectrophotometer. The identity of the purified compound $\mathbf{1}$ was assessed by comparison of its NMR and MS data with data from the literature [22] (Additional file 1).

\section{Biological assays}

The fractions as well as E1 and E2 and 1 were tested against the 3D7 $P$. falciparum strain according to the 
protocol described above. The cytotoxic and haemolytic properties of 1 were also evaluated, as well as its antiplasmodial activity against the W2 chloroquino-resistant strain. We used the same method as described for the crude extracts.

\section{Results and discussion}

In vitro and in vivo anti-plasmodial activity of crude extracts

All eight tested extracts were found to be active against both chloroquine-sensitive 3D7 and -resistant W2 strains of $P$. falciparum $\left(\mathrm{IC}_{50}<50 \mu \mathrm{g} / \mathrm{ml}\right)$. $\mathrm{IC}_{50}$ values obtained with crude extracts are detailed in Table 1 , as well as extraction yields from plants $(\mathrm{w} / \mathrm{w})$. Dichloromethane, diethylether, ethylacetate, and methanol extracts were found to be highly active with $\mathrm{IC}_{50} \leq 5 \mu \mathrm{g} / \mathrm{ml}$, while hydroethanolic and hot water extracts displayed a promising activity $\left(\mathrm{IC}_{50} \leq 15 \mu \mathrm{g} / \mathrm{ml}\right)$. Petroleum ether and hexane extracts showed a lower level of activity.

The levels of activity observed with the dichloromethane, methanol and hot water extracts were about twice as high as the anti-plasmodial $\mathrm{IC}_{50}$ values obtained for the same extracts in the previous study. That previous study was conducted with a batch of $D$. tomentosa also collected in Burkina Faso, at the same time of year but in 2007 and in a different area (and with samples from stock maintained in less adequate storage conditions) [20]. The anti-plasmodial activity obtained with this new batch was found to be in the same range as can be observed with Artemisia annua extracts [38]. The anti-plasmodial activity of the hot water extract supports the traditional use of this plant to treat malaria and is an interesting result when considering further prospects for its local valorization.
In vivo experiments with methanol, hydroethanolic and aqueous extracts of $D$. tomentosa whole plant confirmed the anti-plasmodial activity of this Asteraceae. Both treatments given intraperitoneally (methanol and hydroethanolic extracts, $100 \mathrm{mg} / \mathrm{kg}$ ) displayed an inhibition of parasitaemia in the range of $40-60 \%$ at days 4 and 7. Unfortunately, both extracts were found to be toxic when the dose was increased to $200 \mathrm{mg} / \mathrm{kg} /$ day, i. p. (all the mice died before day 4). Both treatments given by oral route (hydroethanolic and hot water extracts, $300 \mathrm{mg} / \mathrm{kg}$ ) showed a much lower activity at day 4, but at day 7 the inhibition of Plasmodium growth was in the same range as for the extracts given intraperitoneally. Detailed results are presented in Figure 1.

The inhibition of parasitaemia was thus maintained (for ip-tested extracts and Cinchona control extract) or improved (for po-tested extracts) between days 4 and 7, in contrast with chloroquine, for which the activity was high at day 4 but clearly decreased at day 7 . The prolonged activity obtained with the plant extracts against the parasite indicates either a long half-life of the active compounds in the extract, or the implication of metabolization in the activity with production of active metabolites. That (as well as the gastrointestinal resorption process) could explain the delayed effect observed with oral treatments.

\section{Cytotoxic and haemolytic activity of crude extracts}

Additional in vitro studies concerning the haemolytic potential and the cytotoxic activity on normal human fibroblasts were also carried out in order to check the anti-plasmodial selectivity of $D$. tomentosa. Results are detailed in Table 1.

Table 1 In vitro anti-plasmodial, cytotoxic and haemolytic activity of crude extracts and pure compound (1) obtained from Dicoma tomentosa $(n=3)$

\begin{tabular}{|c|c|c|c|c|c|c|c|}
\hline Pure compound & $\begin{array}{l}\text { Yield (in the } \\
\text { plant) }\end{array}$ & $\begin{array}{c}\mathrm{IC}_{50} 3 \mathrm{D} 7 \mu \mathrm{g} / \mathrm{ml} \\
(\mu \mathrm{M})\end{array}$ & $\begin{array}{c}\mathrm{I} C_{50} \mathrm{~W} 2 \mu \mathrm{g} / \mathrm{ml} \\
(\mu \mathrm{M})\end{array}$ & $\begin{array}{c}\mathrm{IC} \mathrm{C}_{50} \mathrm{WI} 38 \mu \mathrm{g} / \mathrm{ml} \\
(\mu \mathrm{M})\end{array}$ & $\begin{array}{c}\mathrm{SI} \\
3 \mathrm{D} 7\end{array}$ & $\begin{array}{c}\text { SI } \\
\text { W2 }\end{array}$ & $\begin{array}{l}\text { Haemolysis } \\
(\%)\end{array}$ \\
\hline $\begin{array}{l}\text { Compound } 1=\text { urospermal-15-O-acetate } \\
(\mathrm{MM}=320.34)\end{array}$ & $0.64 \%$ & $\begin{array}{c}0.92 \pm 0.05 \\
(=2.87 \pm 0.16)\end{array}$ & $\begin{array}{c}0.77 \pm 0.25 \\
(=2.41 \pm 0.78)\end{array}$ & $\begin{array}{c}3.03 \pm 0.18 \\
(=9.47 \pm 0.56)\end{array}$ & 3.3 & 3.9 & $<1 \%$ \\
\hline Extracts & Yield (\%) & $\begin{array}{c}\mathrm{IC}_{50} 3 \mathrm{D} 7 \\
(\mu \mathrm{g} / \mathrm{ml})\end{array}$ & $\begin{array}{l}\mathrm{IC} \mathrm{C}_{50} \mathrm{~W} 2 \\
(\mu \mathrm{g} / \mathrm{ml})\end{array}$ & $\begin{array}{c}\mathrm{IC}_{50} \mathrm{WI} 38 \\
(\mu \mathrm{g} / \mathrm{ml})\end{array}$ & $\begin{array}{c}\mathrm{SI} \\
\text { 3D7 }\end{array}$ & $\begin{array}{c}\mathrm{SI} \\
\mathrm{W} 2\end{array}$ & $\begin{array}{l}\text { Haemolysis } \\
(\%)\end{array}$ \\
\hline Petroleum ether & $1.8 \%$ & $23.2 \pm 3.1$ & $21.2 \pm 2.2$ & $22.0 \pm 0.6$ & 0.9 & 1.0 & $<1 \%$ \\
\hline Hexane & $1.7 \%$ & $18.7 \pm 2.9$ & $17.7 \pm 1.2$ & $32.9 \pm 4.0$ & 1.8 & 1.9 & $<1 \%$ \\
\hline Dichloromethane & $5.4 \%$ & $3.4 \pm 1.2$ & $1.9 \pm 0.2$ & $11.5 \pm 0.4$ & 3.3 & 6.1 & $<1 \%$ \\
\hline Diethylether & $3.4 \%$ & $3.9 \pm 0.6$ & $4.8 \pm 0.7$ & $6.5 \pm 1.4$ & 1.6 & 1.3 & $<1 \%$ \\
\hline Ethylacetate & $4.1 \%$ & $4.4 \pm 1.1$ & $4.6 \pm 0.3$ & $5.9 \pm 0.6$ & 1.3 & 1.3 & $<1 \%$ \\
\hline Methanol & $11.1 \%$ & $5.8 \pm 2.0$ & $3.0 \pm 0.5$ & $19.9 \pm 5.4$ & 3.5 & 6.7 & $<1 \%$ \\
\hline Ethanol 50\% (v/v) & $16.2 \%$ & $12.9 \pm 3.0$ & $9.7 \pm 1.1$ & $28.4 \pm 2.9$ & 2.2 & 2.9 & $<1 \%$ \\
\hline Hot water & $20.3 \%$ & $12.8 \pm 2.4$ & $6.7 \pm 1.0$ & $47.2 \pm 2.9$ & 3.7 & 7.0 & $<1 \%$ \\
\hline
\end{tabular}

$\mathrm{SI}=$ selectivity index $=\mathrm{IC}_{50(\mathrm{WI} 38)} / \mathrm{IC} \mathrm{C}_{50(3 \mathrm{D} 7 \text { or } \mathrm{W} 2 \text {, respectively) }}$

Standard drugs: artemisinin (3D7): IC $\mathrm{F}_{50}=0.0067 \pm 0.0018 \mu \mathrm{g} / \mathrm{ml}$; artemisinin (W2): $\mathrm{C}_{50}=0.0034 \pm 0.0009 \mu \mathrm{g} / \mathrm{ml}$; chloroquine $(3 \mathrm{D} 7): \mathrm{IC}{ }_{50}=0.016 \pm 0.004 \mu \mathrm{g} / \mathrm{ml}$; chloroquine (W2): $I C_{50}=0.35 \pm 0.08 \mu \mathrm{g} / \mathrm{ml}$; camptothecin (WI-38): $I C_{50}=0.029 \pm 0.011 \mu \mathrm{g} / \mathrm{ml}$. 


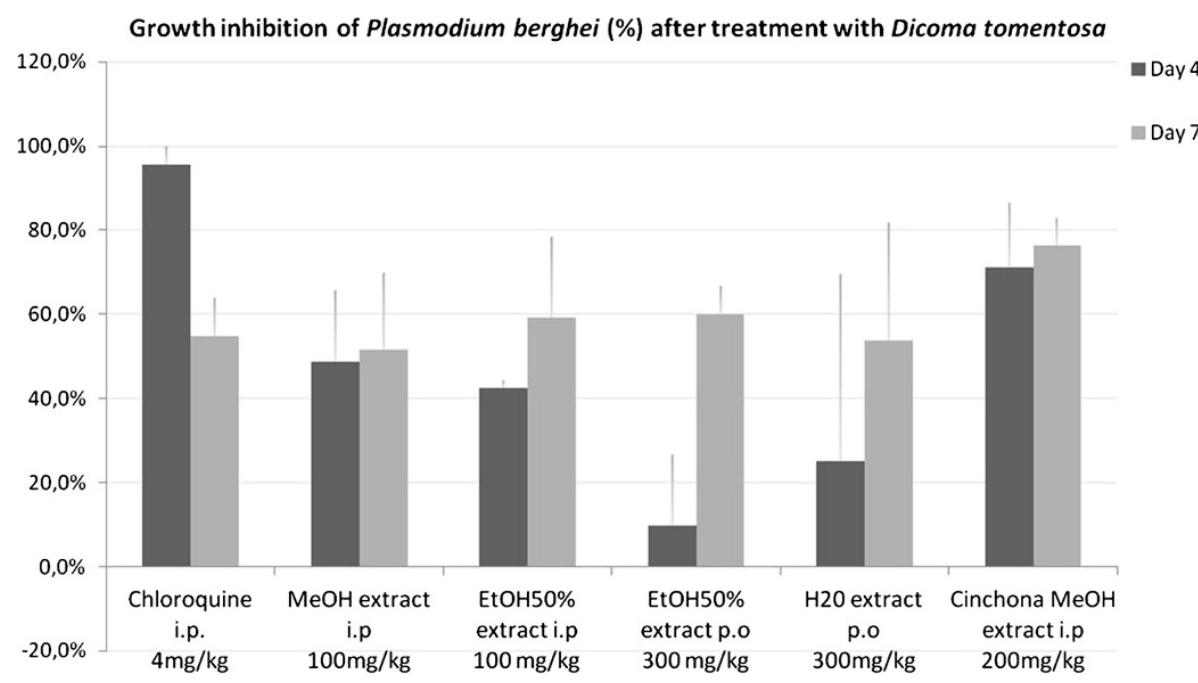

Figure 1 In vivo anti-plasmodial activity is expressed by the inhibition of the growth of Plasmodium berghei in infected mice treated with Dicoma tomentosa extracts compared to a non-treated negative control group of mice (growth $=100 \%$ ). Standard drug = chloroquine (4 mg/kg, ip) and Cinchona succirubra stem bark methanol extract ( $200 \mathrm{mg} / \mathrm{kg}$, ip) $\mathrm{MeOH}=$ methanol;

$\mathrm{EtOH} 50 \%=$ Ethanol/Water 50\% (v/v); H2O = Hot water

No extract was found to exhibit significant red blood cells lysis activity with a percentage of haemolysis $<1 \%$ for all tested extracts $($ conc $=100 \mu \mathrm{g} / \mathrm{ml})$. This indicates that anti-plasmodial activity is not correlated with haemolysis of red blood cells but with a real action against the parasite.

However, all eight extracts were found to be quite cytotoxic on WI38 cells ( $\mathrm{IC}_{50}$ values from 5.9 to $47.2 \mu \mathrm{g} /$ $\mathrm{ml}$ ) and showed a low to moderate selectivity (SI from 0.9 to 7.0 , depending on the extract and the plasmodial strain).

\section{Bioguided fractionation: isolation and identification of the} major active compound

A bioguided fractionation was carried out in order to identify the compound(s) responsible for the anti-plasmodial activity.

Preliminary TLC analysis of the $\mathrm{CH}_{2} \mathrm{Cl}_{2}$ crude extract revealed the presence of some major terpenic compounds in the plant, especially one grey spot ( $\mathrm{Rf} \sim 0.65$ ), using the sulphuric vanillin reagent. The intensity of this grey spot, named "compound 1", seemed to be correlated with the in vitro anti-plasmodial activity of the different tested extracts (Additional file 2).

For the bioguided fractionation and depending on the results obtained with the eight crude extracts, powdered plant was first extracted by hexane (E1), followed by dichloromethane (E2 = "defatted extract" - yield $=3.1 \%$ ).

E2 was submitted to preparative reversed-phase HPLC to give 16 fractions (F1-F16). The activity of the extracts and fractions was evaluated against P. falciparum 3D7 strain. $\mathrm{IC}_{50}$ values of $\mathrm{E} 1$ and $\mathrm{E} 2$ were 36.9 and $2.0 \mu \mathrm{g} / \mathrm{ml}$, respectively. E2 containing compound $\mathbf{1}$ as the major compound was found to be even more active than the crude dichloromethane extract, while E1, found to contain the other major terpenes in TLC analysis, was much less active.

All tested fractions obtained from E2 were found to possess high or promising anti-plasmodial activity, with $\mathrm{IC}_{50}$ values ranging from $0.95 \mu \mathrm{g} / \mathrm{ml}$ (F4 and F5) to $6.9 \mu \mathrm{g} / \mathrm{ml}$ (F16).

The significant activity detected in several fractions with different TLC profiles means that several compounds can be said to contribute to the overall in vitro anti-plasmodial properties of $D$. tomentosa dichloromethane extract. However, major compound $\mathbf{1}$ - the grey spot - was the main constituent of the two most active fractions F4 and F5 (respectively $10.2 \mathrm{mg}$ and $67.3 \mathrm{mg}=25.84 \% \mathrm{E} 2(\mathrm{w} / \mathrm{w})$ ) and this compound could therefore be considered as the major active compound in the plant.

Compound 1, a terpene, was finally isolated as a pure compound after an additional preparative TLC step on F4 and F5 and was submitted to UV, MS/MS and NMR analysis. Compound $\mathbf{1}$ was identified as urospermal A15-O-acetate, a melampolide-type sesquiterpene lactone (Figure 2). Its identity was confirmed by comparison of its spectral profile with spectral data available for known compounds in D. tomentosa [22]. Melampolides are 10membered ring sesquiterpene lactones. They can be considered a subgroup of germacranolides but with a 1,10 cis-double bond configuration.

Yield of urospermal A-15-O-acetate was estimated to $20.7 \%(w / w)$ of the dichloromethane extract (E2), corresponding to $0.64 \%(\mathrm{w} / \mathrm{w})$ of the dried plant. 


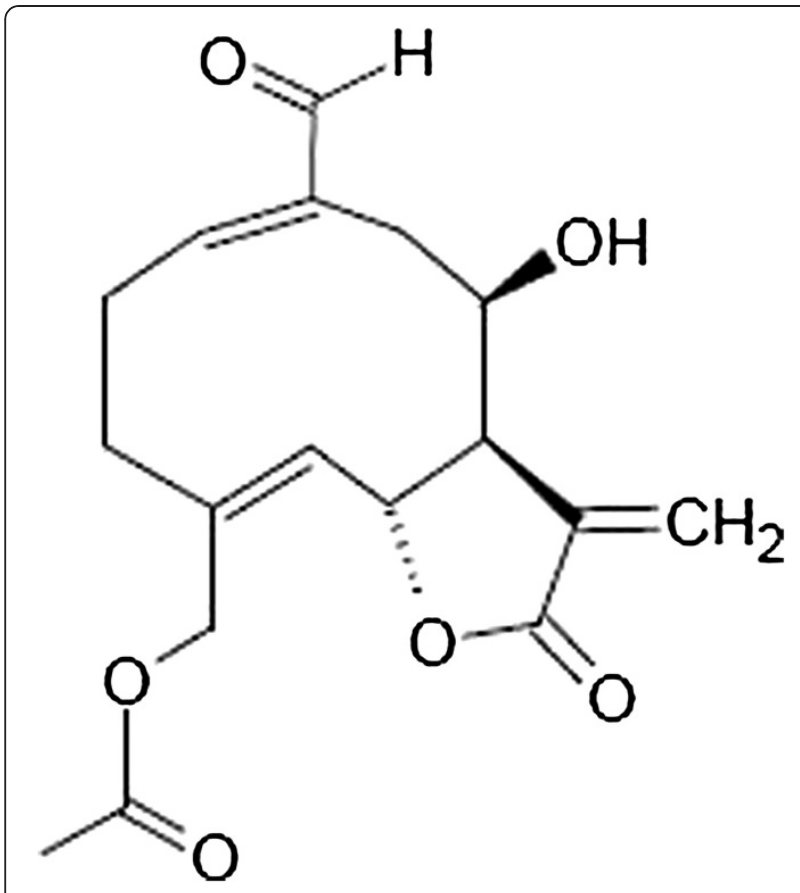

Figure 2 urospermal A-15-O-acetate (MM = 320.34).

\section{Anti-plasmodial, cytotoxic and haemolytic properties of urospermal A-15-0-acetate}

Purified compound 1 was also tested for its anti-plasmodial, cytotoxic and haemolytic properties. Results are presented in Table 1. Urospermal A-15-O-acetate was found to display a very strong anti-plasmodial activity with $\mathrm{IC}_{50}$ $<1 \mu \mathrm{g} / \mathrm{ml}$ against both chloroquine-sensitive and -resistant P. falciparum strains. The contribution of this active compound to the activity of the dichloromethane extract (E2) can be estimated to $62.1 \%$, according to the method described by Deharo and Ginsburg [15]. This confirmed that urospermal A-15-O-acetate could be considered as the main active compound of the plant. It is likely that other minor closely related sesquiterpene lactones - such as the other germacranolides and melampolides already described in the plant [22,23] - also displayed additive/ synergistic anti-plasmodial activity, as attested by the significant activity detected in almost all the fractions. Products from other phytochemical classes, such as flavonoids (already described in the plant [27-30]) could also play some role in the overall anti-plasmodial effect by several mechanisms, as widely described for A. annua [38,39].

No significant haemolytic activity was detected for $\mathbf{1}$. However, this sesquiterpene lactone appeared to be cytotoxic with $\mathrm{IC}_{50}=3.0 \mu \mathrm{g} / \mathrm{ml}$ on WI38 human fibroblasts. The selectivity index $(\mathrm{SI}=3.3)$ was the same as those obtained with the crude $\mathrm{CH}_{2} \mathrm{Cl}_{2}$ extract, which suggests that this major anti-plasmodial compound is the main cytotoxic product in the plant.
Urospermal A-15-O-acetate has already been described as a major compound of $D$. tomentosa by Bolhmann et al. [22] for a batch collected in South Africa. The present study is, however, the first report of the compound's antiplasmodial and cytotoxic properties. Moreover, this compound has never been described in any other plant.

Recently, another plant from the same genus, Dicoma anomala ssp gerrardii was described for its anti-plasmodial activity [40]. The main active compound in that plant was also a sesquiterpene lactone but of the eudesmanolide-type and represented $0.0013 \%$ (w:w) of the dried plant powder. Cytotoxic activity was also detected for this compound in that study.

Many sesquiterpene lactones isolated from Asteraceae have already been described as anti-plasmodial and cytotoxic in the literature, such as (pseudo)guaianolides, eudesmanolides and also germacranolides/melampolides (e g, tagitinin C from Tithonia diversifolia [41] and recently acanthospermolide derivatives from Acanthospermum hispidum [42]). Structure-activity relationship studies have shown that the $\alpha$-methylene- $\gamma$-lactone moeity (or more widely, at least one potentially reactive $\alpha, \beta$-unsaturated bond) is the main element needed for anti-plasmodial or cytotoxic activity of such compounds, and that antiprotozoal activity is significantly correlated with cytotoxicity $[43,44]$. The low selectivity of such compounds can be explained by the chemical reactivity of the $\alpha, \beta$-unsaturated bond, especially towards free thiol groups (e g, cysteine residues in enzymes and transcription factors).

\section{Conclusions}

Dicoma tomentosa showed promising anti-plasmodial properties through in vitro and in vivo tests performed in the present study, and this supports the traditional use of this plant. However, the plant's lack of selectivity would urge caution in its consumption by the local population. Further studies (e g, regarding genotoxicity, acute/chronic toxicity) are needed to assess the safe use of the plant.

We found that the main active compound of the plant, urospermal A-15-O-acetate, showed a promising anti-plasmodial activity with a low but real selectivity. Its mechanism of action is currently under study. A pharmacomodulation process may need to be undertaken in order to decrease the compound's toxicity while maintaining (or improving) its activity. On the other hand, its cytotoxic activity could also be investigated in the field of cancerology.

\section{Additional files}

Additional file 1: Spectroscopic data of compound 1. 
Additional file 2: TLC analysis of $D$. tomentosa extracts tested in vitro for antiplasmodial activity.

\section{Abbreviations}

WHO: World Health Organization; ACT: Artemisinin combination therapy; ITM: Improved traditional medicine; SI: Selectivity index; CQ: Chloroquine; HPLC: High performance liquid chromatography; TLC: Thin layer chromatography; ip: Intra-peritoneal; po: Per os.

\section{Competing interests}

The authors declare that they have no competing interests.

\section{Authors' contributions}

OJ carried out the in vitro and in vivo anti-plasmodial activity assays and the bioguided fractionation as well as the in vitro cytotoxic and haemolytic assays. She also analysed the data and drafted the manuscript. MT and LA contributed to data analysis and critically revised the manuscript. JPN participated in plant selection and collection, analysed botanical/ ethnomedicinal data and contributed to the revision of the manuscript. PDM and JBN assisted with data analysis and the revision of the manuscript. MF contributed to the design of experiments, helped in in vivo anti-plasmodial assay and data analysis and assisted in the correction of the draft manuscript. All the authors read and approved the final manuscript.

\section{Acknowledgments}

The authors wish to thank the local "Jardins du monde" team in Burkina Faso for their help in collecting plant samples and ethnobotanical information regarding Dicoma tomentosa. They would also like to thank $\operatorname{Pr} A$ Chariot (GIGA, University of Liège, Belgium) for providing technical support and installations to perform the cytotoxicity assay, Dr J Widart for her precious help in mass spectrometry analysis and Pr E Robbrecht (National Herbarium of Belgium, Meise) for identification of the plant.

\section{Author details}

${ }^{1}$ Laboratoire de Pharmacognosie, Centre Interfacultaire de Recherche du Médicament (CIRM), Université de Liège, Av. de I'Hôpital 1, CHU-B36, B-4000 Liège, Belgium. ${ }^{2}$ Association Jardins du Monde, 15, rue St Michel, 29190 Brasparts, France. ${ }^{3}$ Laboratoire de Microbiologie médicale, Université de Liège, Av. de I'Hôpital 1, B23, B-4000 Liège, Belgium. ${ }^{4}$ Unité de Formation et de Recherche en Sciences de la Santé, Université de Ouagadougou, 03 BP 7021 Ouagadougou 03, Burkina Faso.

Received: 25 May 2012 Accepted: 15 August 2012

Published: 21 August 2012

\section{References}

1. WHO: Guidelines for the treatment of malaria. Geneva: World Health Organization; 2010

2. Egan TJ: Artemisinin-resistant $P$. falciparum: can the genie be put back in the bottle? Future Microbiol 2009, 4:637-639.

3. Dondorp AM, Yeung S, White L, Nguon C, Day NPJ, Socheat D, von Seidlein $L$ : Artemisinin resistance: current status and scenarios for containment. Nat Rev Microbiol 2010, 8:272-280.

4. Phyo AP, Nkhoma S, Stepniewska K, Ashley EA, Nair S, McGready R, Moo Cl, Al-Saai S, Dondorp AM, Lwin KM, Singhasivanon P, Day NPJ, White NJ, Anderson TJC, Nosten F: Emergence of artemisinin-resistant malaria on the western border of Thailand: a longitudinal study. Lancet 2012, doi:10.1016/S0140-6736(12)60484-X. In press.

5. Batista R, Silva Ade J Jr, de Oliveira AB: Plant-derived antimalarial agents: new leads and efficient phytomedicines. Part II. Non-alkaloidal natural products. Molecules 2009, 14:3037-3072.

6. Bero J, Frédérich M, Quetin-Leclercq J: Antimalarial compounds isolated from plants used in traditional medicine. J Pharm Pharmacol 2009, 61:1401-1433

7. Bero J, Quetin-Leclercq J: Natural products published in 2009 from plants traditionally used to treat malaria. Planta Med 2011, 77:631-640.

8. Kaur K, Jain M, Kaur T, Jain R: Antimalarials from nature. Bioorg Med Chem 2009, 17:3229-3256.

9. Nogueira CR, Lopes LMX: Antiplasmodial Natural Products. Molecules 2011, $16: 2146-2190$
10. WHO: Traditional medicine Fact sheet $N^{\circ} 134$. Geneva: WHO Media centre; 2008.

11. WHO: Guidelines on registration of traditional medicines in the WHO African region. Brazzaville: WHO Regional Office for Africa; 2010.

12. Willcox M, Burford G, Bodeker G: An overview of ethnobotanical studies on plants used for the treatment of malaria. In Traditional Medicinal Plants and Malaria. Boca Raton: CRC Press; Willcox M, Bodeker G, Rasoanaivo P; 2004:187-197.

13. Willcox M, Bodecker G: Traditional herbal medicine for malaria. Br Med J 2004, 329:1156-1159.

14. Rasoanaivo P, Wright C, Willcox M, Gilbert B: Whole plant extracts versus single compounds for the treatment of malaria: synergy and positive interactions. Malar J 2011, 10(Suppl 1):S4.

15. Deharo $\mathrm{E}$, Ginsburg $\mathrm{H}$ : Analysis of additivity and synergism in the antiplasmodial effect of purified compounds from plant extracts. Malar $J$ 2011, 10(Suppl 1):S5.

16. Ginsburg H, Deharo E: A call for using natural compounds in the development of new antimalarial treatments - an introduction. Malar $J$ 2011, 10(Suppl. 1):S1.

17. Willcox M, Graz B, Falquet J, Diakite C, Giani S, Diallo D: A "reverse pharmacology" approach for developing an antimalarial phytomedicine. Malar J 2011, 10(suppl1):S8

18. Graz B, Willcox M, Diakite C, Falquet J, Dackuo F, Sidibe O, Giani S, Diallo D: Argemone mexicana decoction versus artesunate-amodiaquine for the management of malaria in Mali: policy and public-health implications. Trans R Soc Trop Med Hyg 2010, 104:33-41

19. Yerbanga RS, Lucantoni L, Lupidi G, Dori GU, Tepongning NR, Nikiéma JB, Esposito F, Habluetzel A: Antimalarial plant remedies from Burkina Faso: Their potential for prophylactic use. J Ethnopharmacol 2012, 140:255-260

20. Jansen $\mathrm{O}$, Angenot $L$, Tits $M$, Nicolas JP, De Mol $P$, Nikiéma JB, Frédérich $M$ : Evaluation of 13 selected medicinal plants from Burkina Faso for their antiplasmodial properties. J Ethnopharmacol 2010, 130:143-150.

21. Jansen $O$, Frédérich $M$, Tits $M$, Angenot L, Cousineau S, Bessot L, Crunet C, Nicolas JP: Ethnopharmacologie et paludisme au Burkina Faso: sélection de 13 espèces à potentialités antiplasmodiales méconnues. Ethnopharmacologia 2008, 41:74-78.

22. Bohlmann F, Singh P, Jakupovic J: Naturally occurring terpene derivatives. Part 428. Germacranolides from Dicoma tomentosa. Phytochem 1982, 21:2122-2124.

23. Zdero C, Bohlmann F: Sesquiterpene lactones from Dicoma species. Phytochem 1990, 29:183-187.

24. Krishna V, Natani K, Singh P: Oxygenated germacranolides from Compositae and their taxonomic significance. J Indian Chem Soc 2003, 80:971-977.

25. Mehta R, Arora OP, Mehta M: Chemical investigation of some Rajasthan desert plants. Indian J Chem Sect B 1981, 20B:834.

26. Catalan CAN, Borkosky SA, Joseph-Nathan P: The secondary metabolite chemistry of the Subtribe Gochnatiinae (Tribe Mutisieae, Family Compositae). Biochem Syst Ecol 1996, 24:659-718.

27. Aquil M, Akinniyi J, Ndahi NP: Flavonoids from Dicoma tomentosa. Global J Pure App/ Sci 1998, 4:135-137.

28. Aqil M, Khan IZ: Dicomatin - a new flavone glycoside from Dicoma tomentosa. Global J Pure App/ Sci 1999, 5:357-358.

29. Aqil M, Khan IZ: Three flavone glycosides from Dicoma tomentosa Cass. Ultra Sci Phys Sci 1999, 11:378-380.

30. Aqil M, Khan IZ, Dimari GA: A new flavone glycoside from Dicoma tomentosa. Global J Pure Appl Sci 2001, 7:273-275.

31. Frédérich M, Jacquier MJ, Thepenier P, De Mol P, Tits M, Philippe G, Delaude C, Angenot L, Zeches-Hanrot M: Antiplasmodial activity of alkaloids from various Strychnos species. J Nat Prod 2002, 65:1381-1386.

32. Makler MT, Ries JM, Williams JA, Bancroft JE, Piper RC, Gibbins BL, Hinrichs DJ: Parasite lactate-dehydrogenase as an assay for Plasmodium falciparum drug-sensitivity. AmJTrop Med Hyg 1993, 48:739-741.

33. Kenmogne $M$, Prost $E$, Harakat $D$, Jacquier MJ, Frédérich $M$, Sondengam LB, Zeches M, Waffo-Teguo P: Five labdane diterpenoids from the seeds of Aframomum zambesiacum. Phytochem 2006, 67:433-443.

34. Pink R, Hudson A, Mouries MA, Bendig M: Opportunities and challenges in antiparasitic drug discovery. Nat Rev Drug Discov 2005, 4:727-740.

35. Fidock DA, Rosenthal PJ, Croft SL, Brun R, Nwaka S: Antimalarial drug discovery: efficacy models for compound screening. Nat Rev Drug Discov 2004, 3:509-520 
36. Robert S, Baccelli C, Devel P, Dogné JM, Quetin-Leclercq J: Effects of leaf extracts from Croton zambesicus Müell. Arg. on hemostasis.

J Ethnopharmacol 2010, 128:641-648.

37. Frederich M, Tits M, Goffin E, Philippe G, Grellier P, De Mol P, Hayette MP, Angenot $L:$ In vitro and in vivo antimalarial properties of isostrychnopentamine, an indolomonoterpenic alkaloid from Strychnos usambarensis. Planta Med 2004, 70:520-525.

38. Phillipson DJ, Wright CW: Can ethnopharmacology contribute to the development of antimalarial agents? J Ethnopharmacol 1991, 32:155-165

39. Ferreira JFS, Luthria DL, Sasaki T, Heyerick A: Flavonoids from Artemisia annua $\mathrm{L}$. as antioxidants and their potential synergism with artemisinin against malaria and cancer. Molecules 2010, 15:3135-3170.

40. Becker JWW, van der Merwe MM, van Brummelen AC, Pillay P, Crampton BG, Mmutlane EM, Parkinson C, van Heerden FR, Crouch NR, Smith PJ, Mancama DT, Maharaj VJ: In vitro anti-plasmodial activity of Dicoma anomala subsp. gerrardii (Asteraceae): identification of its main active constituent, structure-activity relationship studies and gene expression profiling. Malar J 2011, 10:295.

41. Goffin E, Ziemons E, De Mol P, Do Céude Madureira M, Martins AP, Proença da Cunha A, Philippe G, Tits M, Angenot L, Frederich M: In vitro antiplasmodial activity of Tithonia diversifolia and identification of its main active constituent: tagitinin C. Planta Med 2002, 68:543-545.

42. Ganfon H, Bero J, Tchinda AT, Gbaguidi F, Gbenou J, Moudachirou M, Frederich M, Quetin-Leclercq J: Antiparasitic activities of two sesquiterpenic lactones isolated from Acanthospermum hispidum D.C. J Ethnopharmacol 2012, doi:10.1016/j.jep.2012.03.002. In Press.

43. Scotti MT, Fernandes MB, Ferreira MJP, Emerenciano VP: Quantitative structure activity relationship of sesquiterpene lactones with cytotoxic activity. Bioorg Med Chem 2007, 15:2927-2934.

44. Schmidt TJ, Nour AMM, Khalid SA, Kaiser M, Brun R: Quantitative structureantiprotozoal activity relationships of sesquiterpene lactones. Molecules 2009, 14:2062-2076.

doi:10.1186/1475-2875-11-289

Cite this article as: Jansen et al: Anti-plasmodial activity of Dicoma

tomentosa (Asteraceae) and identification of urospermal A-15-O-acetate as the main active compound. Malaria Journal 2012 11:289.

\section{Submit your next manuscript to BioMed Central and take full advantage of:}

- Convenient online submission

- Thorough peer review

- No space constraints or color figure charges

- Immediate publication on acceptance

- Inclusion in PubMed, CAS, Scopus and Google Scholar

- Research which is freely available for redistribution 